\title{
A Qualitative Study of Reactive Powder Concrete using X-Ray Diffraction Technique.
}

\author{
M k Maroliya \\ Assistant professor, Applied Mechanics Dept, Faculty of Technology \& Engineering, M.S. University of Baroda, \\ Vadodara,
}

\begin{abstract}
The development of $X$-ray diffraction it became possible to intregrate the method into existing laboratory automation systems for process and quality control to provide a means of online monitoring. A reliable, precise and very reproducible method to quantify the relative phase abundances of cementitious product is to use X-Ray diffraction method. This analysis is apowerful method for the determination of quantative phase amounts in multiple phase mixtures. In a present study an optimized composition of RPC in different curing regime has been studied qualitatively in XRD at regular interval of time, Better understanding hydration and microstructure changes and mineralogical changes has been studied.
\end{abstract}

Key words-RPC, XRD, ultra high strength concrete, microstructure.

\section{INTRODUCTION}

$\mathrm{X}$-ray powder diffraction (XRD), is an instrumental technique that is used to identify minerals, as well as other crystalline materials. In many geologic investigations, XRD complements other mineralogical methods, including optical light microscopy, electron microprobe microscopy, and scanning electron microscopy. XRD provides the researcher with a fast and reliable tool for routine mineral identification. XRD is particularly useful for identifying fine-grained minerals and mixtures or intergrowths of minerals that may not lend themselves to analysis by other techniques. XRD can provide additional Information beyond basic identification. If the sample is a mixture, XRD data can be analyzed to determine the proportion of the different minerals present. Other information obtained can include the degree of crystalline of the mineral(s) present, possible deviations of the minerals from their ideal compositions (presence of element substitutions and solid solutions), the structural state of the minerals (which can be used to deduce temperatures and (or) pressures of formation), and the degree of hydration for minerals that contain water in their structure. Some mineralogical samples analyzed by XRD are too fine grained to be identified by optical light microscopy. XRD does not, however, provide the Quantitative compositional data obtained by the electron microprobe or textural and qualitative compositional data obtained by the scanning electron microscope. The three-dimensional structure of no amorphous materials, such as minerals, is defined by regular, repeating planes of atoms that form a crystal lattice. When a focused Xray beam interacts with these planes of atoms, part of the beam is transmitted, part is absorbed by the sample, part is refracted and scattered, and part is diffracted. Diffraction of an X-ray beam by a crystalline solid is analogous to diffraction of light by droplets of water, producing the familiar rainbow. X-rays are diffracted by each mineral differently, depending on what atoms make up the crystal lattice and how these atoms are arranged.

\section{METHODOLOGY}

In X-ray powder diffractometry, X-rays are generated within a sealed tube that is under vacuum. A current is applied that heats a filament within the tube, the higher the current the greater the number of electrons emitted from the filament. This generation of electrons is analogous to the production of electrons in a television picture tube. A high voltage, typically 15-60 kilovolts, is applied within the tube. This high voltage accelerates the electrons, which then hit a target, commonly made of copper. When these electrons hit the target, X-rays are produced. The wavelength of these X-rays is characteristic of that target. These X-rays are collimated and directed onto the sample, which has been ground to a fine powder (typically to produce particle sizes of less than 10 microns). A detector detects the $\mathrm{X}$-ray signal; the signal is then processed either by a microprocessor or electronically, converting the signal to a count rate. Changing the angle between the X-ray source, the sample, and the detector at a controlled rate between preset limits is an X-ray scan. When an X-ray beam hits a sample and is diffracted, we can measure the distances between the planes of the atoms mat constitute the sample by applying Bragg's Law. Bragg's Law is $\eta \lambda=2 \mathrm{~d} \sin \theta$, where the integer $\mathrm{n}$ is the order of the diffracted beam, 1 is the wavelength of the incident X-ray beam, $d$ is the distance between adjacent planes of atoms (the d-spacing's), 
and $\theta$ is the angle of incidence of the X-ray beam. Since we know 1 and we can measure $\theta$, we can calculate the d-spacing. The geometry of an XRD unit is designed to accommodate this measurement (fig.).6.7 the characteristic set of d-spacing's generated in a typical X-ray scan provides a unique "fingerprint" of the mineral or minerals present in the sample. When properly interpreted, by comparison with standard reference patterns and measurements, this "fingerprint" allows for identification of the material.

$\mathrm{X}$-ray diffraction is widely used to identify crystalline phases, measure crystallite sizes, lattice parameters, Orientation and provide quantitative phase analysis and atomic coordinates. This information is important for relating the production of a material to its structure and hence its properties. As well as being of academic interest, X-ray results are used in patent disputes, forensically and for quality control. it can be also use for identification of cement material.

\subsection{SPECIFICATION OF MATERIALS}

\section{MATERIAL AND COMPOSITION}

Table 1: Specifications of the materials used for RPC

\begin{tabular}{|l|c|l|}
\hline Sample & Specific Gravity & Particle Size Range \\
\hline $\begin{array}{l}\text { Cement } \\
\text { (IS 12269: 1987) }\end{array}$ & 3.15 & $31 \mu \mathrm{m}-7.5 \mu \mathrm{m}$ \\
\hline $\begin{array}{l}\text { Silica fume } \\
\text { (ASTM C1240-97B) }\end{array}$ & 2.2 & $5.3 \mu \mathrm{m}-1.8 \mu \mathrm{m}$ \\
\hline Quartz sand & 2.7 & $5.3 \mu \mathrm{m}-1.3 \mu \mathrm{m}$ \\
\hline $\begin{array}{l}\text { Steel fiber - 13mm } \\
\text { (ASTM A 820-96) }\end{array}$ & 7.1 & Length $13 \mathrm{~mm}$ and dia. $0.45 \mathrm{~mm}$ \\
\hline $\begin{array}{l}\text { Steel fiber - 25mm } \\
\text { (ASTM A 820-96) }\end{array}$ & 7.1 & Length $25 \mathrm{~mm}$ and dia. $0.4 \mathrm{~mm}$ \\
\hline $\begin{array}{l}\text { 20mm Aggregate } \\
\text { (IS. 383:1970) }\end{array}$ & 2.78 & $25 \mathrm{~mm}-10 \mathrm{~mm}$ \\
\hline $\begin{array}{l}\text { 10mm Aggregate } \\
\text { (IS. 383:1970) }\end{array}$ & 2.78 & $12.5 \mathrm{~mm}-4.75 \mathrm{~mm}$ \\
\hline $\begin{array}{l}\text { River sand } \\
\text { (IS 383: 1970) }\end{array}$ & 2.61 & $0.6 \mathrm{~mm}-0.15 \mathrm{~mm}$ \\
\hline
\end{tabular}

\subsection{COMPOSITION OF REACTIVE POWDER CONCRETE.}

RPC is composed of very fine powders (cement, sand, quartz powder and silica fume), steel fibers (optional) and super plasticizer. The super plasticizer, used at its optimal dosage, decreases the water to cement ratio (W/C) while improving the workability of the concrete. A very dense matrix is achieved by optimizing the granular packing of the dry fine powders. These Reactive Powder Concretes have compressive strengths ranging from $160 \mathrm{MPa}$ to $800 \mathrm{MPa}$.

Table 2: Optimzed composition of RPC used in Experimental program (parts by mass)

\begin{tabular}{|l|c|}
\hline Materials & Part by mass of cement \\
\hline Cement & 1 \\
\hline Sand & 1.5 \\
\hline Silica fume or pozzolan & 0.32 \\
\hline Powdered quartz sand & 0.36 \\
\hline Steel fibers & 0.20 \\
\hline Water & 0.23 \\
\hline Super plasticizer & 0.04 \\
\hline
\end{tabular}




\section{RESULT AND DISCUSSION:}

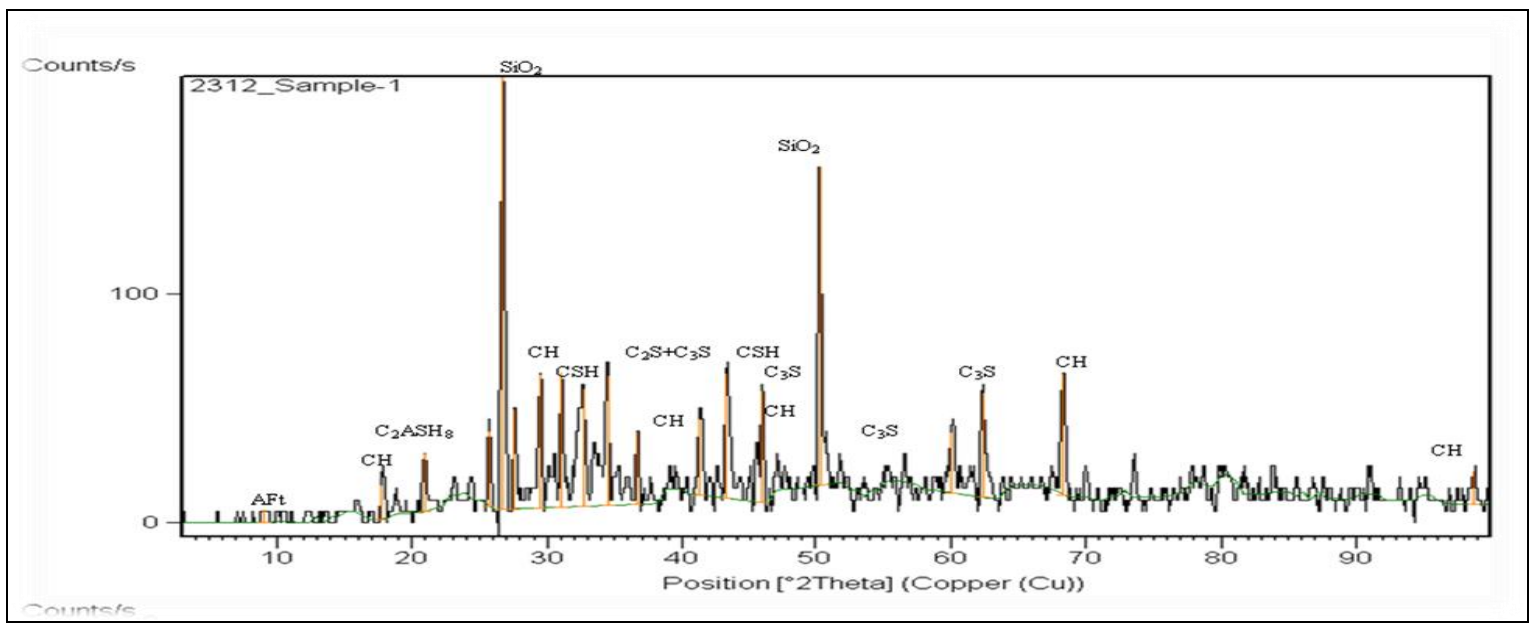

Fig. 1: X-ray diffract grams of RPC after curing for1 day

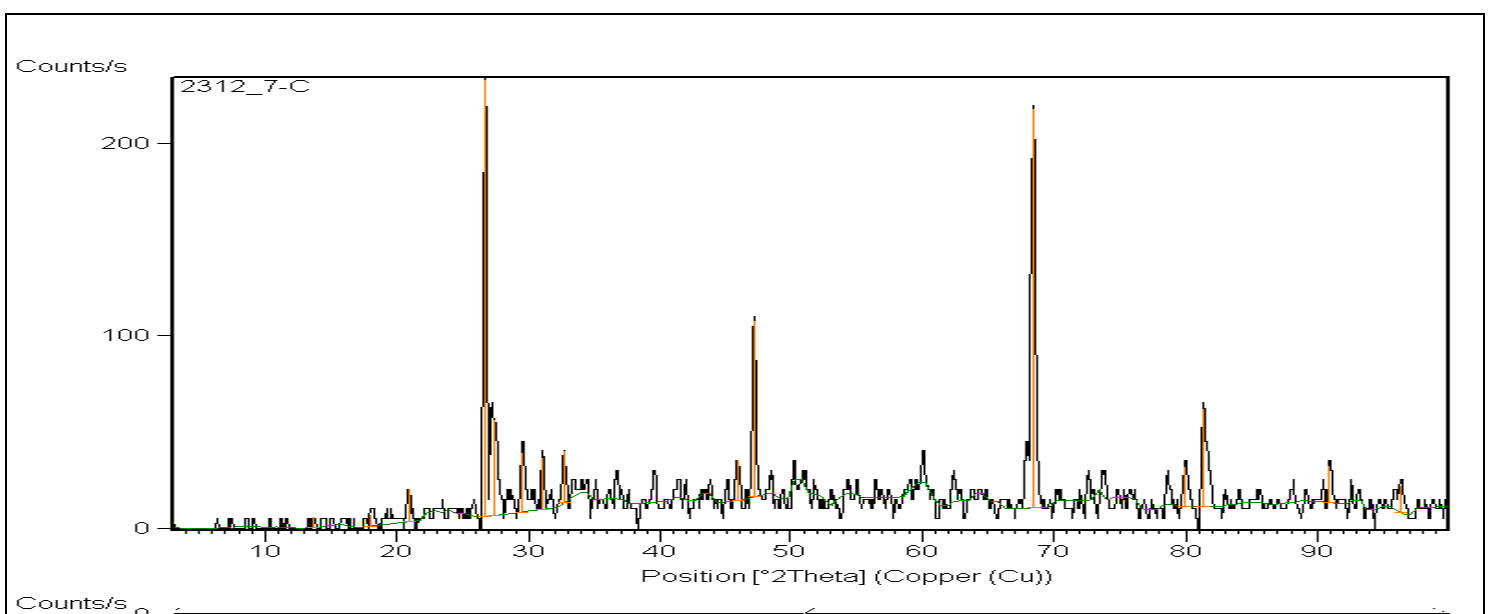

Fig.2 X-ray diffractograms of RPC after curing for 7 days normal curing

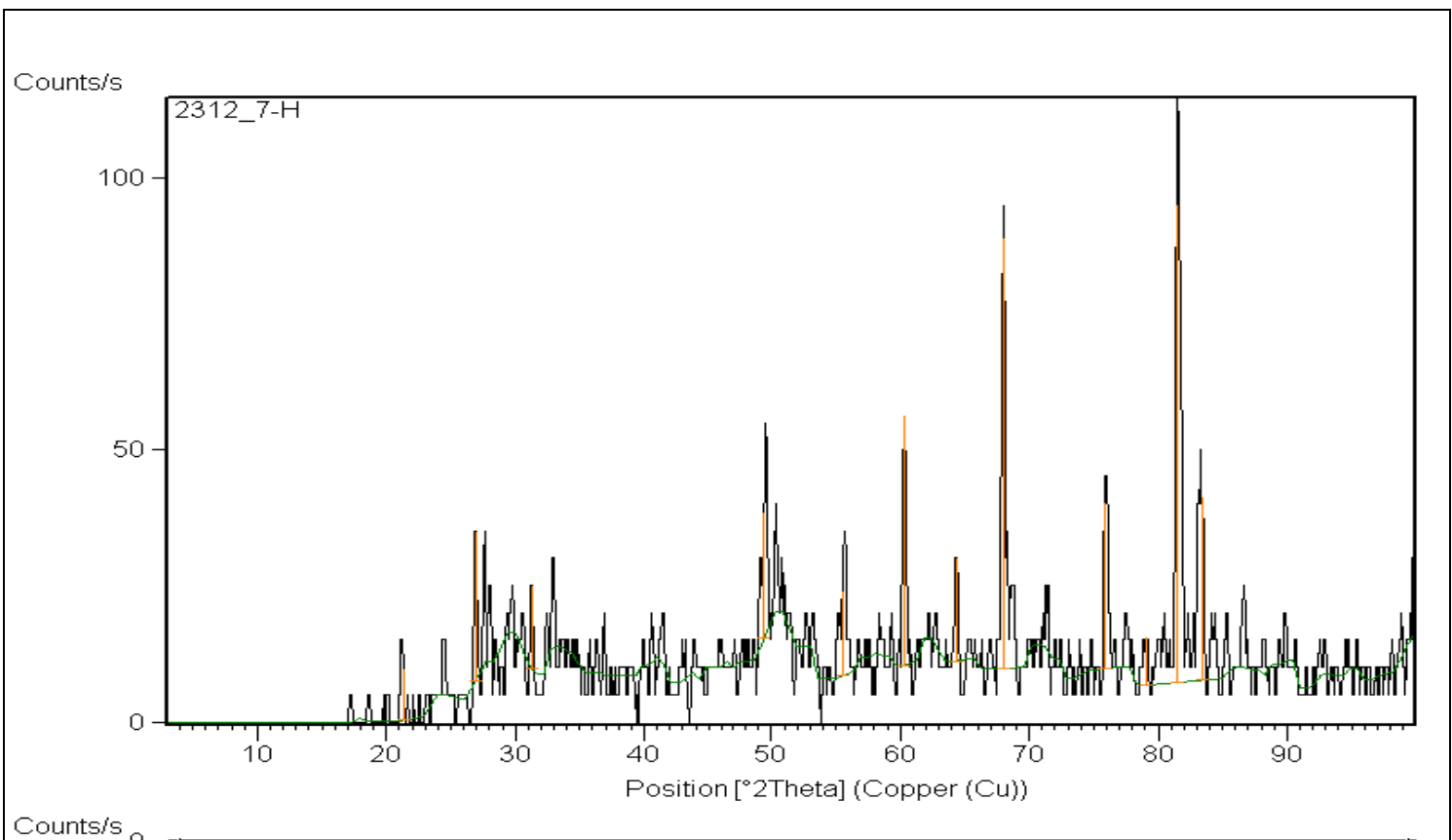

Fig 3: X-ray diffractograms of RPC after curing for 7 days hot curing 


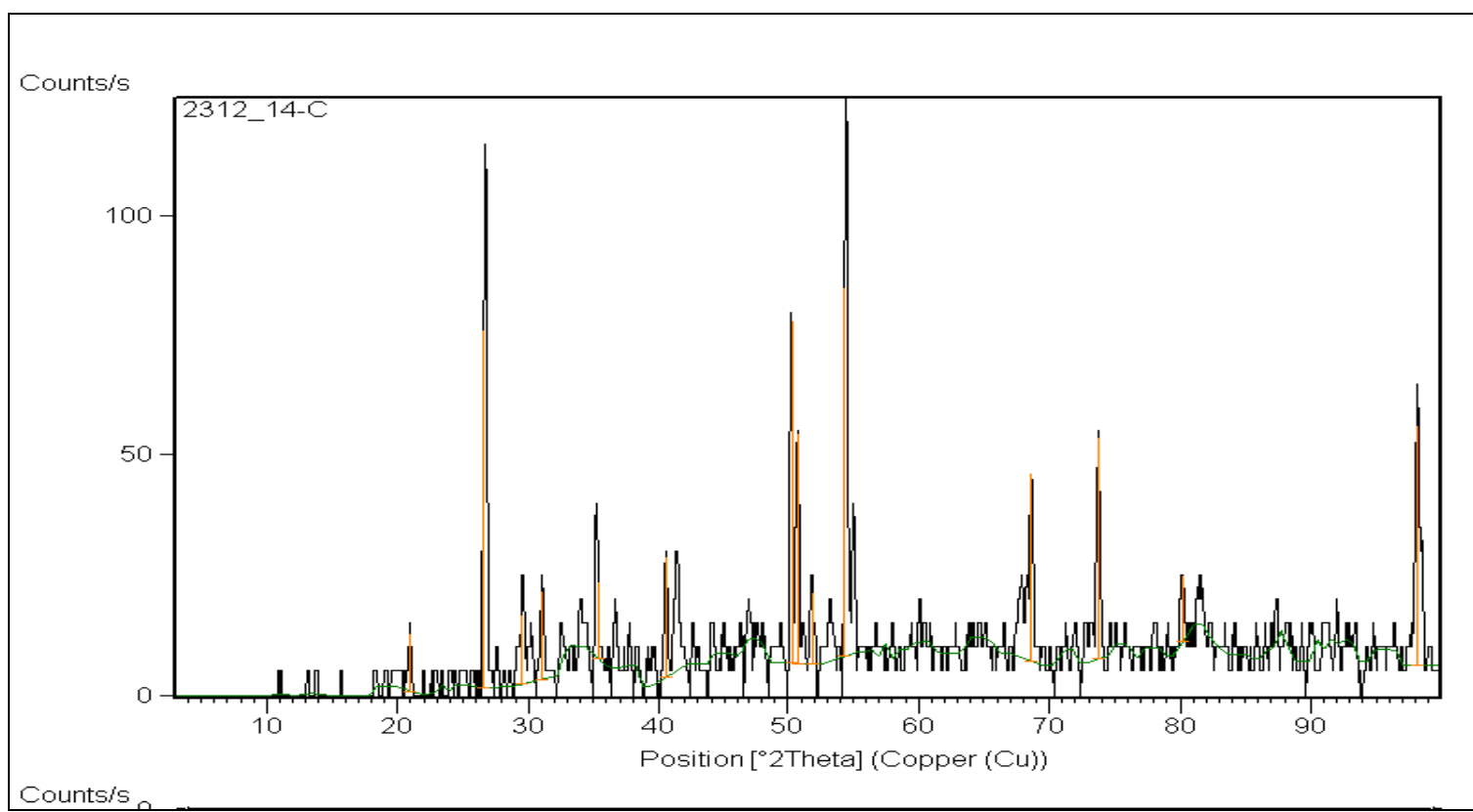

Fig.4: X-ray diffractograms of RPC after curing for 14 days normal curing

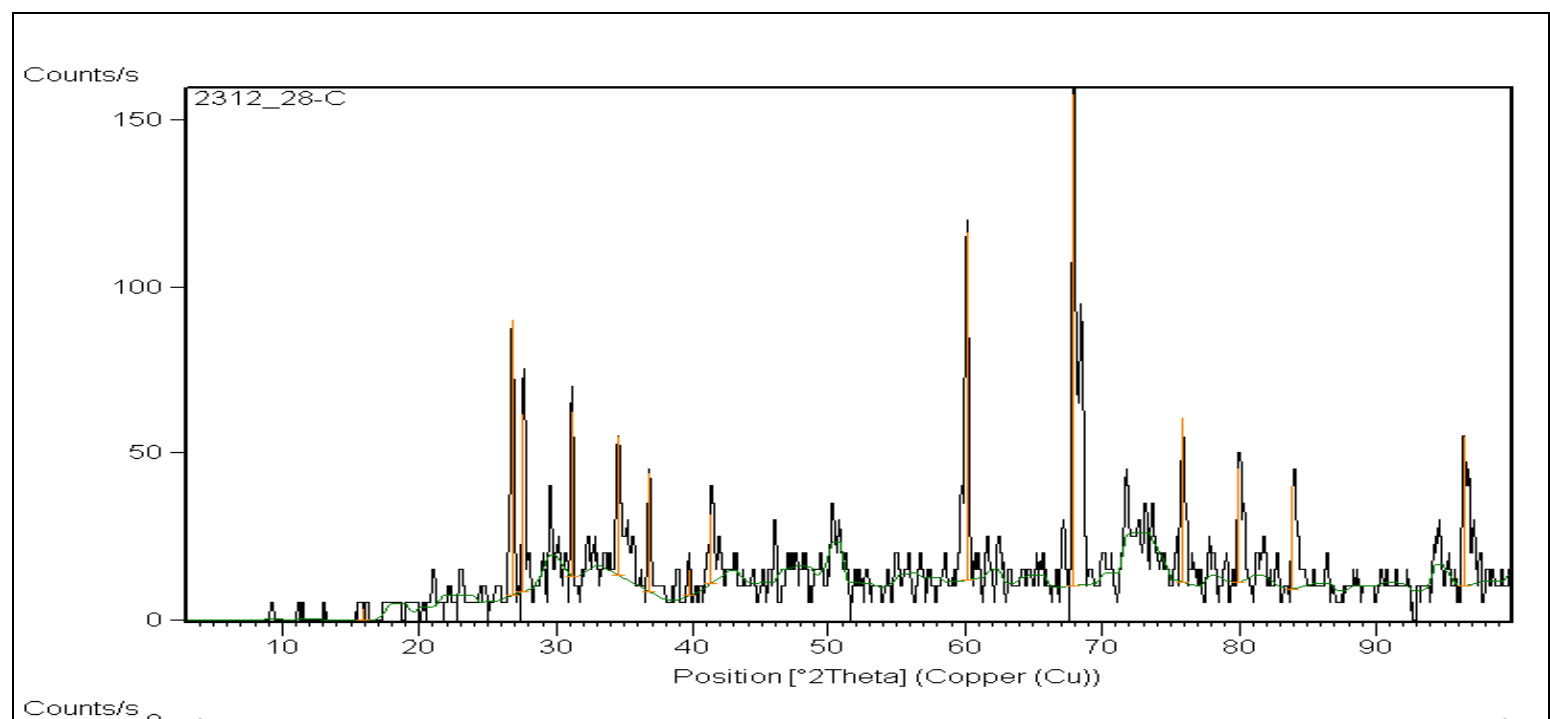

Fig.5: X-ray diffract grams of RPC after curing for 28 days normal curing

Result Fig.1 shows the XRD patterns of bulk paste for $2.0 \%$ of steel fiber Reactive Powder Concrete, which were cured in 28-days water immersion. All of them contained Portlandite $(\mathrm{CH})$ and $\mathrm{SiO}_{2}$ as a major phase. From the diffract grams patterns in sample-1, it was observed that the intensity of $\mathrm{CH}$ is higher and the C-S-H was lower in RPC content mix. It might be indicated that the degree of hydration in RPC with 7days hot was curing $(7-\mathrm{H})$ much higher than the same sample with 28 days normal water curing $(28-\mathrm{C})$. The reason could be that the hot curing provided the buster or accelerating the hydration process for concrete.

Fig.1.to Fig.5 Shows the XRD patterns of bulk pastes for sample-1. All of them contained Portlandite $(\mathrm{CH})$ and $\mathrm{SiO}_{2}$ were the major phases in all samples of RPC. From the diffract gram patterns in Fig.1, it is observed that the intensity of Calcium-Silicate-Hydrate $(\mathrm{C}-\mathrm{S}-\mathrm{H})$ in 7days $(7-\mathrm{H})$ hot water curried and $28 \mathrm{days}$ (28-C) normal water curried was higher than in sample-1(1days normal curried). This may indicate that the degree of hydration in 7days hot water curried and 28days normal water curried concrete with high cement replacement was better than sample-1(1days normal curried) mixes under the same steel fiber contain. Further, the intensities of Portlandite $(\mathrm{CH})$ in sample-1(1days normal curried) were higher than that in 7days hot water curried. The reason might be that the content of $\mathrm{CH}$ was prorated to the creative degree of $\mathrm{C}-\mathrm{S}-\mathrm{H}$. 
This may indicate that the degree of hydration in 7-H concrete with high cement replacement was better than Sample-1, 7-C, 14-C, and 28-C mix under the same sample. Further, the intensities of Portlandite $(\mathrm{CH})$ in Sample-1, 7-C, 14-C and 28-C were higher than 7-H concrete. In this spectra $\mathrm{C}_{3} \mathrm{~S}$ and $\mathrm{C}_{2} \mathrm{~S}$ peaks characteristic of unhydrated cement, are detected, even for high temperature for curing.

\section{CONCLUSIONS}

1. RPC microstructure depends on heat treatment or curried condition.XRD studies made it possible to gain better understanding of the micro structural changes induced due to curing condition. It shows that hot curried water sample led to faster change in microstructure of C-H-S hydrates. Compare to normal water curried sample.

2. It can observe change in the microstructure. The effect of mineral admixture (silica fume and quartz sand) help in developing dance microstructure of RPC.

3. As hydration increases consumption of $\mathrm{CAOH}_{2}$ also can be observed and still there is anhydrated cement is remaining in a powder of RPC.

\section{REFERENCE}

[1] Alexander, M.G., Mackechnie, J.R. and Ballim, Y.(2001) Materials Science of Concrete, Vol. VI, Ed. J. P. Skalny and S. Mindess, American Ceramic Society, , 483- 511

[2] Bakker, R.F.M, (july1983). "Permeability of blended cements concretes", 1 international conference st on the use of fly ash, silica fume, slag and other mineral by products in concrete, , Montebello, Canada, ACI.

[3] Neven Ukrainczyk ${ }^{1}$, Marko Ukrainczyk, Juraj Šipušić, Tomislav Matusinović "XRD and TGA investigation of hardened cement paste degradation" 1Faculty of Chemical Engineering and Technology, University of Zagreb, Marulićev trg 19, HR- 10000 Zagreb, Croatia Institut Ruđer Bošković, Bijenička 54, HR-10 000 Zagreb, Croatia

[4] Neville, A.M., (1995) "Properties of concrete", Pitman, Londre, 4ème edition, ISBN0-582-23070-5.

[5] Serivener.K.L, Bentur.A and P.L.Pratt (1988) "Quantitative Characterization Of The Transition Zone In High Strength Concrete" Advance in cement research, Vol.1 No.4, October Mostafa.Khanzadi , Mohsen.Tadayon , And Hamed.Sepehri "Influence Of Micro And Nano Silica Particles On Mechanical Properties And Permeability Of Concrete ACSGE-2009, Oct 25-27, BITS Pilani, India. 